\title{
A Bibliometric Analysis on Higher Education Curricula Model
}

\author{
Xiao-Song REN \\ School of Management Science \& Engineering \\ Shanxi University of Finance \& Economics \\ Taiyuan, China \\ renxiaosong1986@163.com
}

\author{
Yu-Jia LIU \\ School of Management Science \& Engineering \\ Shanxi University of Finance \& Economics \\ Taiyuan, China \\ lyogajia@163.com
}

\begin{abstract}
The aim of this study is to explore the higher education curriculum model and new ways of talent cultivation. This paper uses the bibliometric method to analyze 1019 existing works of literature in the research field of higher education curriculum model, which are selected from the core collection of Web of science database during 2013 to 2018. We sort out and quantitatively analyze the relevant lite rature of higher education curriculum model. Base on the scientific and intuitive chart data, we analyze the publication time, high-related fields, top journals, high-level rese arch institutions and most cited authors. Moreover several visual knowle dge maps for collaborative network analys is and literature co-citation analysis are made by using CiteSpace software, one of a visualization tool for mapping knowledge domain. Finally, through above quantitative analys is, the results show as follows: (1) the research hotspot focus on the keywords "university education" and "curriculum". (2) the key words "strategy" and "s atisfaction" are likely to be new rese arch frontiers in this field.
\end{abstract}

Keywords-higher education; course mode; bibliometric; citation network

\section{INTRODUCTION}

At present, the higher education curricula model is usually aiming at strengthening discipline knowledge and theoretical understanding, lacking practice [1]. However, learning through the workplace is an effective training strategy for the higher education [2]. Studying in school and learning in a workplace are two major components of professional education, and students must develop professional competence by building meaningful relationships between knowledge and skills [3]. Therefore, the combination of theoretical knowledge learning and practice in school has become the focus of education revolution. In addition, government, industry, students, and employers are paying more attention to students who receive advanced education in practice [4]. It is necessary for colleges and universities to consider the relationship between education and work practice [5]. Some scholars have carried out a systematic literature review on the $3-p$ model of workplace learning [6], and some scholars have proposed different goals for school study and professional education [7]. Establishing balance and consistency is one of the main challenges of curriculum development. Higher Education has strong connection with practice, and the comprehensive ability of talents has become the new core competitiveness.

Shanxi Education Science "12th five-year plan" Project(GH-15031)

Shanxi University ofFinance and Economics School-level Teaching Reform and Innovation Project (2018223)
In order to improve the education curriculum model, it is necessary to analyze the existing research in higher education curriculum model. However, the research is widely dispersed with complex theory and content. The research focuses on qualitative analysis, and the summary of works of literature are mainly literature review, lacking quantitative statistics and collation. This paper will make quantitative statistics in the field of higher education curriculum model from 2013-2018, analyzing the evolution process and the status to know the future trend of education curriculum model in colleges and universities, and put forward research proposals.

\section{METHOD AND DATA}

\section{A. The bibliometric method}

Bibliometric, integrating mathematics, statistics and philology, is a systematic method to quantitatively analyze all knowledge carriers and focus on quantitative analysis. Literature measurement is an effective method to analyze academic journals [8], which can also analyze the research status and de velopment trend of education curriculum model in colleges and universities [9]. Analyzing the core literature, evaluating publications, and investigating the utilization rate of pieces of literature by means of bibliometric analysis can provide direction for future research.

$\mathrm{H}$-index is a mixed quantitative indicator, proposed by Jorge Hirsch in 2005, a physicist at the University of California, San Diego, which could be used to evaluate the academic output of the researchers and the level of the academic output. $\mathrm{H}$-index means that $\mathrm{h}$ numbers of one's total articles are cited at least $\mathrm{h}$ times, which is closely related to bibliometric. Hirsch believes that the $\mathrm{h}$ index can accurately reflect a person's academic achievements, and the higher a person's $h$ index is, the greater the influence of his thesis [10].

In order to analyze the dynamic evolution trend of higher education curriculum model, we analyze the data statistically through Excel and CiteSpace software. This paper studies the hot spots and the frontier by analyzing the general situation and the trend of the relevant literature on education curriculum model from 2013 to 2018 . Through a visual map of knowledge about keyword co-occurrence, author cooperation, and institutional cooperation network, we can obtain the analysis of cited articles to explore the research status and development context of the existing literature. 


\section{B. Data collection}

Due to the authoritative and wide application of web of science core collection in the academic field, this paper uses it as the key database for this research, using "Higher Education Curricula Model" as a theme for the basic retrieval. It mainly analyzes the data of 2013-2018, considering that the literature research in the last five years can better reflect the current research status and research focus. Up to 29 April in 2018, 1019 publications are collected, including articles (94.603\%), review papers $(3.827 \%)$, and other publications. In terms of publication language, English is the most frequently used $(96.176 \%)$, followed by Spanish $(1.667 \%)$, each of the other languages accounts for less than $1 \%$.

\section{RESULT}

\section{A. The performance of different years}

As shown in Fig. 1, No notes the number of publications in every year, and TC stands for the number of cited frequency in every year. The study found that the research of higher education curriculum model shows an increasing trend overall from 2013 to 2018 except 2014. In 2017, the publications reach the top with the number of 215 , but the annual output gap is small. In addition, the annual citation frequency is also increasing gradually. In 2013, the cited frequency is 81 . In addition, the citation frequency reached 308 in 2014. In 2017, the citation frequency reaches the peak of 1701. Obviously, in recent years, the total citation frequency of the articles in this field has increased greatly, and more and more researchers pay attention to this topic. In 2018, the number of published articles and cited frequency reached slack because of the incomplete data, which are collected before April 2018. However, according to the trend, the number of published documents and the cited frequency may create a new peak in 2018.

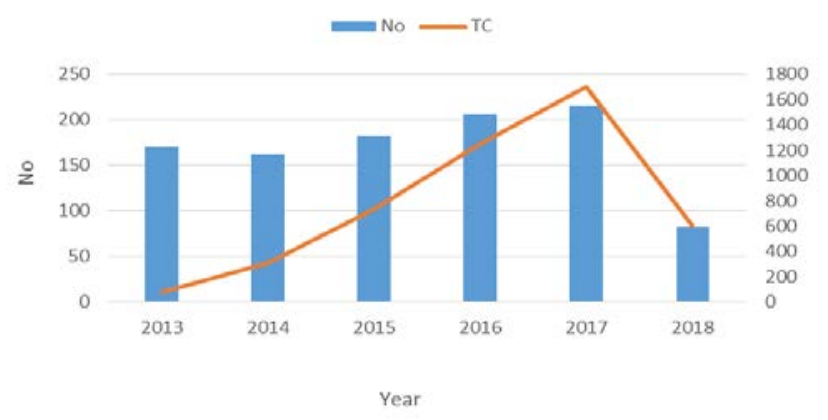

Fig. 1. The number of publications in every year.

Note: the total number of publications, TC: total cited times per year

\section{B. The performance of different journals}

Table 1 shows the top 10 productive journals with 177 published articles accounts for $17.37 \%$ of the total articles from 2013 to 2018. Academic Medicine and BMC Medical Education had the same publications and took the first place with 24 articles $(2.36 \%)$ at the same time, little higher than Journal of Chemical Education, the third journal with 23 articles $(2.26 \%)$. It is found that the gap between the highyielding journals in the field of higher education curriculum model is not obvious, and the distribution of periodicals is dispersed. As shown in Fig.2, the difference in every journal is not significant with a similar annual output, and the trend of change is wavy. Only BMC Medical Education published 11 articles in such a field in 2017. According to the incomplete data of 2018, the Journal of Cleaner Production has been paying more attention to this field recently, and five articles have been published by April 2018 .

TABLE I. THE PERFORMANCE OF DIFFERENT JOURNALS

\begin{tabular}{lll}
\hline JOURNAL NAME & TP & $\%$ \\
\hline ACADEMIC MEDICINE & 24 & 2.353 \\
BMC MEDICAL EDUCATION & 24 & 2.353 \\
JOURNAL OF CHEMICAL EDUCATION & 23 & 2.255 \\
JOURNAL OF CLEANER PRODUCTION & 20 & 1.961 \\
NURSE EDUCATION TODAY & 18 & 1.765 \\
INTERNATIONAL JOURNAL OF & 15 & 1.471 \\
SUSTAINABILITY IN HIGHER EDUCATION & 15 & 1.471 \\
JOURNAL OF SURGICAL EDUCATION & 13 & 1.275 \\
ANATOMICAL SCIENCES EDUCATION & 13 & 1.275 \\
EURASIA JOURNAL OF MATHEMATICS & 12 & 1.176 \\
SCIENCE AND TECHNOLOGY EDUCATION & & \\
STUDIES IN HIGHER EDUCATION &
\end{tabular}

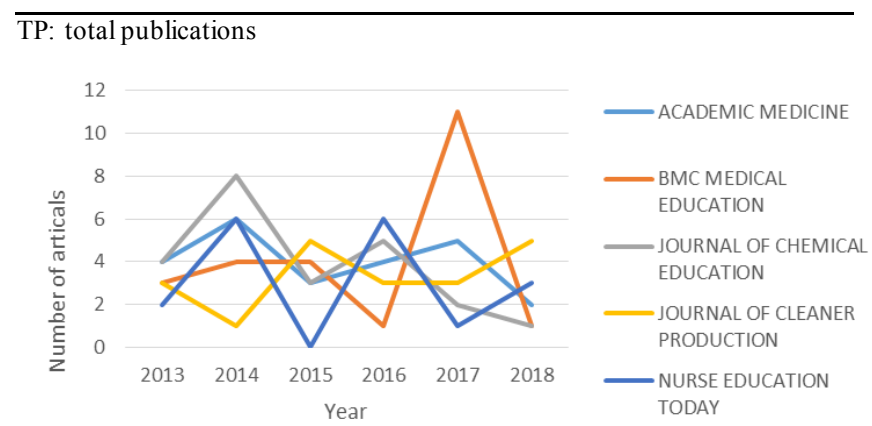

Fig. 2. The performance of different journals

\section{The analysis of research orientation}
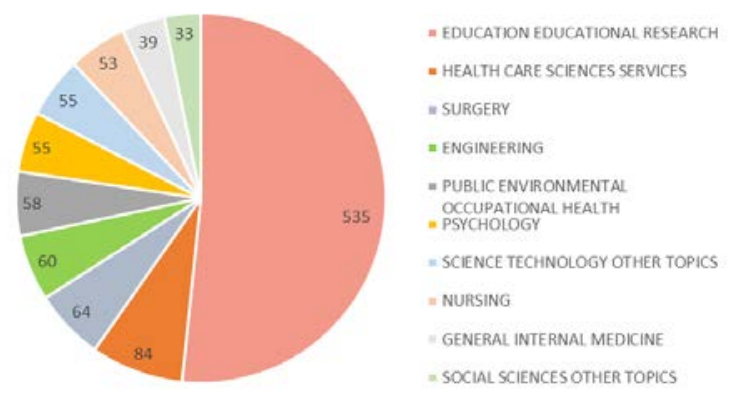

Fig. 3. The analys is of research orientation.

Fig.3 shows the top 10 research orientations of higher education curriculum model from 2013-2018. It shows that the research in this field is mainly about education educational research recently, and the related literature are 535 (52.5\%), much higher than health care sciences services, the second orientation with 84 articles (8.24\%). The number of studies on surgery, engineering, public environmental occupational health, psychology, science technology and other nursing topics is 
similar. The number of studies in general internal medicine and others social sciences topics is relatively small, accounting for $3.83 \%$ and $3.24 \%$ respectively.

\section{The analysis of the hot spot based on keywords}

The statistical analysis of keywords is an effective way to determine the scientific direction and explore the development of science and technology (Garfield, 1990). Through the analysis of Citespace software, of the 1019 articles, 170 keywords are used, of which $61.8 \%$ appeare less than 10 times, $30.6 \%$ appeare more than or equal to 10 times but less than 50 times. Table 2 lists 13 keywords which appeared more than 50 times in the research field of higher education curricula model, ranked by usage frequency. According to the research, "education" is a keyword with the highest frequency (298), but the node center is only 0.06. And other high-frequency keywords include curriculum, model, student, higher education, etc. The node centralities of higher education and curriculum are 0.13 and 0.1 respectively, which are the key nodes in such a field sorted by the node centrality.

TABLE II. THE ANALYSIS OF THE KEYWORDS

\begin{tabular}{llll}
\hline Freq. & Cited References & Centrality & Year \\
\hline 298 & education & 0.06 & 2013 \\
222 & curriculum & 0.1 & 2013 \\
161 & model & 0.07 & 2013 \\
152 & student & 0.04 & 2013 \\
124 & higher education & 0.13 & 2013 \\
90 & medical education & 0.05 & 2013 \\
76 & performance & 0.02 & 2013 \\
73 & knowledge & 0.06 & 2013 \\
68 & skill & 0.02 & 2013 \\
62 & simulation & 0.04 & 2013 \\
58 & program & 0.02 & 2013 \\
54 & school & 0.04 & 2013 \\
52 & science & 0.04 & 2013 \\
\hline
\end{tabular}

TP: total publications

Table 3 shows the analysis results of the research frontiers, ranked by Burst Term. The results show that the number of keywords bursting in 2013, 2014 and 2016 is 7, 3 and 2 respectively. According to the two emerging keywords in 2016, the latest research frontier term is strategy and satisfaction, with the burst rate 3.25 and 0.06 respectively. It may be the focus of future research in this field.

TABLE III. THE ANALYSIS OF THE RESEARCH FRONTIERS

\begin{tabular}{lllll}
\hline Burst & Key Words & TP & Centrality & Year \\
\hline 3.31 & primary care & 9 & 0 & 2013 \\
3.25 & strategy & 11 & 0 & 2016 \\
2.94 & high school/introductory chemistry & 8 & 0.01 & 2013 \\
\hline 2.71 & resident & 23 & 0.03 & 2013 \\
2.57 & curriculum design & 7 & 0 & 2013 \\
2.44 & satisfaction & 13 & 0.06 & 2016 \\
2.41 & faculty & 14 & 0.06 & 2014 \\
\hline
\end{tabular}

\begin{tabular}{lllll}
\hline \multicolumn{5}{c}{ Cont. to TABLE III } \\
\hline 2.2 & teaching & 6 & 0 & 2013 \\
2.2 & diversity & 6 & 0.03 & 2013 \\
2.2 & dental education & 6 & 0 & 2013 \\
2.16 & mathematics & 17 & 0.03 & 2014 \\
2.01 & physical education & 11 & 0.02 & 2014 \\
\hline TP: total publications
\end{tabular}

\section{E. Publication features of different countries}

\section{1) The performance of different countries}

Table 4 lists the top 10 most productive countries in the field of higher education curriculum model from 2013 to 2018. The USA is the most productive country in such a field with 474 publications from 2013 to 2018 , accounting for $46.5 \%$ of total publications, which has the h-index up to 21 . However, Australia, the second productive country, has a large gap with the United States, having 85 publications and the h-index of 13. Other productive countries such as England, Canada and Spain, all have h-index above ten. China is ranked sixth in the number of posts with 48 publications, and the h-index is 7. Germany, Taiwan and the Netherlands have fewer publications. It shows that China has been ranked in the middle with appropriate publications, but the h-index is low, indicating that China's influence in such a field is relatively small. Compared with China, Germany has a higher h-index than China, which means its quality and influence are relatively high, although the publications is less than China.

TABLE IV. THE PERFORMANCE OF PRODUCTIVE COUNTRIES

\begin{tabular}{llll}
\hline Country/region & TP & TP $(\%)$ & H-index \\
\hline USA & 474 & 46.516 & 21 \\
AUSTRALIA & 85 & 8.342 & 13 \\
ENGLAND & 76 & 7.458 & 13 \\
CANADA & 58 & 5.692 & 11 \\
SPAIN & 49 & 4.809 & 7 \\
PEOPLES R CHINA & 48 & 4.711 & 7 \\
GERMANY & 46 & 4.514 & 9 \\
TAIWAN & 34 & 3.337 & 7 \\
NETHERLANDS & 32 & 3.14 & 7 \\
ISRAEL & 19 & 1.865 & 6 \\
\hline
\end{tabular}

TP: total publications, TP (\%): the ratio of one country's publications to the total number of publications.

\section{2) Academic cooperation}

Fig. 4 shows the academic collaboration among different countries through the analysis of Citespace software. Node size means the number of productions in each country through international collaboration. The bigger the node, the stronger in international cooperation the country is. As shown in Fig. 4, the USA is the most active country. In addition, Australia and England are also active. According to the clustering analysis, in the top 10 productive countries, Australia, England, Peoples R China and Netherlands cooperate closely, and Germany has a cooperative relationship with Israel. Although the United States does not cooperate with other countries in table 4 , it has cooperation with Turkey, Scotland, India, etc. 


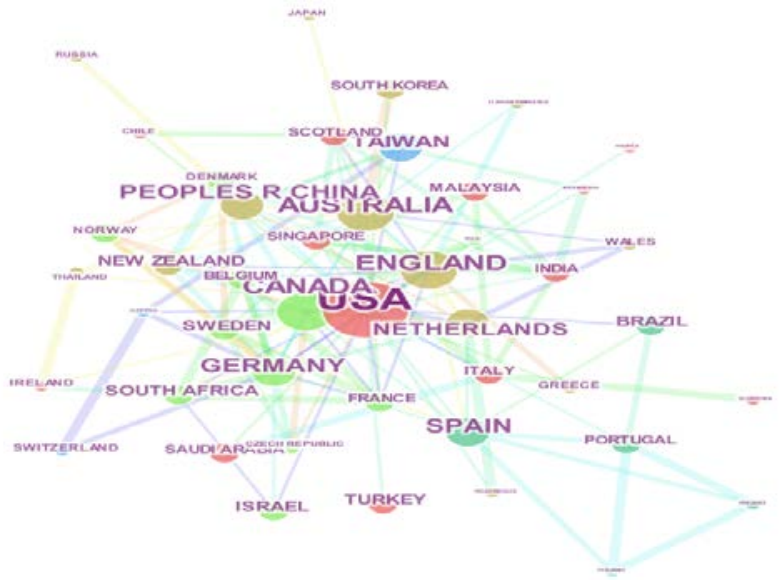

Fig. 4. The cooperation between different countries

\section{F. Cooperation analysis of institutes}

At present, according to the Web of Science, there are 167 institutions studying on higher education curricula model. Of the 167 institutes, 118 institutes cooperated with other institutions, accounting for $70.66 \%$. Table 5 describes the ten most productive institutes in the research of higher education curricula model during 2013-2018. Univ California San Francisco is not only the most productive research institution but also the key node in clustering, with a centrality of 0.13 and more cooperation with other institutions. Stanford Univ is following, with a volume of 14 and a centricity of 0.11 . Among these 10 institutes, Univ, San Francisco, and NYU have cooperative relations. At the same time, there is a cooperative relationship between Stanford Univ, Harvard Univ and Univ Penn, and a mutual cooperation between Northwestern Univ and Univ Michigan. Fig.5 shows the cooperative relationship between the major different organizations. Active academic communications between research institutions around the world promote the optimal allocation of scientific resources and accelerate the development of international research theory, promoting the innovation and perfection of education curriculum model research in colleges and universities.

TABLE V. THE ANALYSIS OF THE INSTITUTES

\begin{tabular}{cclcc}
\hline TP & Centrality & Institute Name & Year & Cluster \\
\hline 18 & 0.13 & Univ Calif San Francisco & 2013 & 0 \\
14 & 0.11 & Stanford Univ & 2014 & 1 \\
14 & 0.06 & Univ Washington & 2013 & 3 \\
13 & 0.05 & Northwestern Univ & 2013 & 2 \\
12 & 0.03 & Mayo Clin & 2013 & 4 \\
11 & 0.09 & Harvard Univ & 2014 & 1 \\
11 & 0.09 & Univ Penn & 2014 & 1 \\
10 & 0.02 & Univ Michigan & 2013 & 2 \\
8 & 0.11 & NYU & 2014 & 0 \\
7 & 0.07 & Univ Queensland & 2014 & 6 \\
\hline TP. total publications & & &
\end{tabular}

TP: total publications

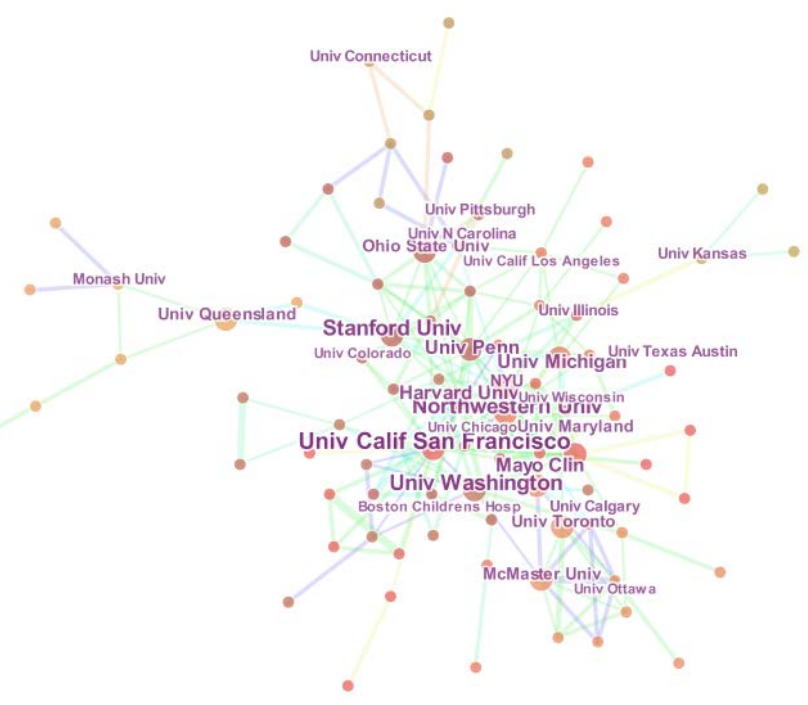

Fig. 5. Collaboration relationships between different institutions

\section{G. The analysis of cited articles}

Citation analysis is a research method for information measurement, which reveals the quantitative characteristics and inner laws through analyzing the references and cited phenomena of scientific journals, papers, and authors. Table 6 shows the top ten cited literature, including the author's name, the year of publication, literature source and other specific information. The analysis found that 521 articles are cited twice or more, but only 3 works of literature are cited more than 10 times. Sugand K (2010), Drake RL (2009) and Cook DA (2011) are cited 15, 14 and 10 times respectively, which have high reference value in the study of education curriculum model in colleges and universities. In addition, Schwarz CV(2009), Frenk J(2010), Lozano R(2010), Lozano R(2013) were all cited 9 times, which also have some reference value. Most of the other papers are cited 2 times.

TABLE VI. THE ANALYSIS OF THE MOST HIGHLY CITED ARTICLES

\begin{tabular}{clc}
\hline CC & References & Cluster \\
\hline 15 & Sugand K, 2010, ANAT SCI EDUC, V3, P83 & 0 \\
14 & Drake RL, 2009, ANAT SCI EDUC, V2, P253 & 0 \\
10 & $\begin{array}{l}\text { Cook DA, 2011, JAMA-J AM MED ASSOC, V306, } \\
\text { P978 }\end{array}$ & 4 \\
9 & Schwarz CV, 2009, J RES SCI TEACH, V46, P632 & 1 \\
9 & Frenk J, 2010, LANCET, V376, P1923 & 3 \\
9 & Lozano R, 2010, J CLEAN PROD, V18, P637 & 2 \\
9 & Lozano R, 2013, J CLEAN PROD, V48, P10 & 6 \\
8 & National Research Council, 2012, FRAM K 12 SCI & 1 \\
8 & ED PRA, V, P & 16 \\
8 & Kern DE, 2009, CURRICULUM DEV MED E, V, P & 1 \\
\hline CC: citation counts
\end{tabular}

As shown in Fig.6, we can know from the clustering analysis that the cluster label \#0 is medical education. A total of 151 papers are cited, and the earliest citation was published in 2006. Cluster label \#1 is high school, which has 93 cited literature. 


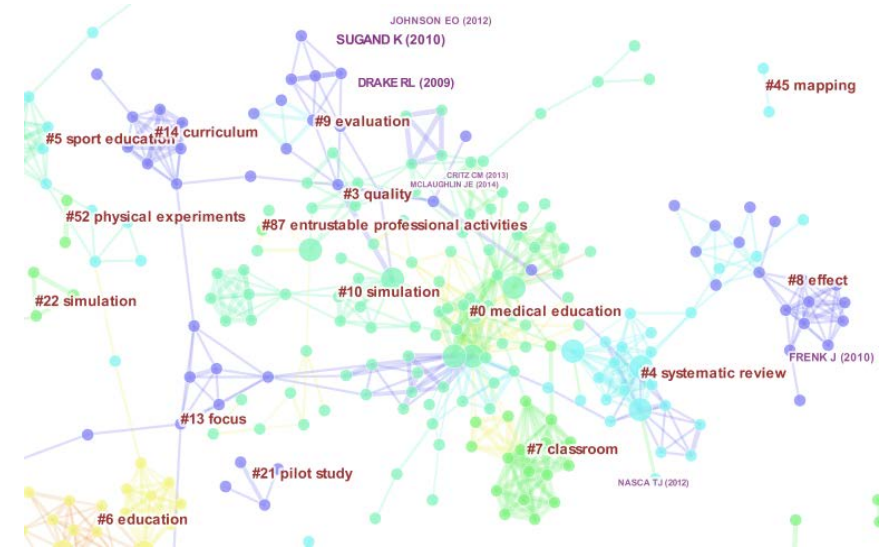

Fig. 6. The analys is of cited articles

\section{CONClusion}

Education is the foundation of social development, and the way to adapt to social needs can not only improve the quality of talents but also be crucial to the development of the country. The research on higher education curriculum model plays an important role in changing the traditional model of teaching and exploring better methods to cultivate talent. 1019 publications associated with higher education curricula model from 2013 to 2018 based on the SCI and SSCI databases are retrieved by using bibliometric methods, and $94.603 \%$ of which were articles. The study reveals that the literature on higher education curricula model has grown gradually over the past 5 years. The findings and results are summarized from the following three aspects:

\section{A. Research trends}

On the whole, the research of higher education curriculum shows an increasing trend according to the annual number of posts. In recent years, the citation frequency of articles in this field has gradually increased, and more and more scholars have begun to pay attention to the research in this field. Most of the research mainly focused on education educational research in 2013-2018, with 535 references $(52.5 \%)$, more than other orientations. And from 2013 to 2018, the research hotspot is centered on the keywords "university education" and "curriculum". The key words "strategy" and "satisfaction" in 2016 are likely to be new research orientations in this field.

\section{B. National research}

At the global research scale of higher education curricula model in recent years, USA is the leading country with the most publications, international cooperation, and highest academic influence. At the same time, the most productive institution (Univ Calif San Francisco) is also from the USA. The gap between other countries and the United States is large, and the difference is reflected in the number of posts and the h- index. In addition, China is ranked in the middle according to the number of publications, but the influence is small. In contrast, although Germany has a smaller volume than China, its h-index is higher, and the article is influential.

\section{Citation analysis}

From the perspective of citation analysis, cited references are not so much, but the reference value is large. Sugand K(2010), Drake RL(2009) and Cook DA(2011) are cited more frequently, laying a foundation for the research of higher education curriculum mode. High cited literature focus on the medical education and high school and other fields, so these are the core of this field.

\section{ACKNOWLEDGMENT}

The authors gratefully acknowledge the financial support from Shanxi Education Science "12th five-year plan" Project under grant no.GH-15031, Shanxi University of Finance and Economics School-level Teaching Reform and Innovation Project under grant no.2018223, and the China Scholarship Council (CSC) under grant no.201508140081.

\section{REFERENCES}

[1] Zitter I, Hoeve A, Bruijn E D. A Design Perspective on the Schoolwork Boundary: A Hybrid Curriculum Model [J]. Vocations \& Learning, 2016, 9(1):111-131.

[2] Poortman C L, Reenalda M, Nijhof W J, et al. Workplace Learn ing in Dual Higher Professional Education[J]. Vocations \& Learning, 2014, 7(2):167-190.

[3] Schaap H, Baartman L, Bruijn E D. Students' Learning Processes during School-Based Learning and Workplace Learning in Vocational Education: A Review[J]. Vocations \& Learning, 2012, 5(2):99-117.

[4] Billett S. Integrating learning experiences across tertiary education and practice settings: A socio-personal account [J]. Educational Research Review, 2014, 12(3):1-13.

[5] Griffiths T, Guile D. A Connective Model of Learn ing: The Imp lications for Work Process Knowledge [J]. European Educational Research Journal, 2003, 2(1):56-73.

[6] Tynjälä P. Toward a 3-P Model of Workplace Learning: a Literature Review[J]. Vocations \& Learning, 2013, 6(1):11-36.

[7] Akkerman S F, Bakker A. Crossing Boundaries between School and Work During Apprenticeships [J]. Vocations \& Learning, 2012, 5(2):153-173.

[8] Zhang P, Yan F, Du C. A comprehensive analysis of energy management strategies for hybrid electric vehicles based on bibliometrics $[\mathrm{J}]$. Renewable \& Sustainable Energy Reviews, 2015, 48:88-104.

[9] Fu H Z, Ho Y S, Sui Y M, et al. A bibliometric analysis of solid waste research during the period 1993-2008[J]. Waste Management, 2010, 30(12):2410-7.

[10] Hirsch J E. An Index to Quantify an Individual's Scientific Research Output [J]. Proceedings of the National Academy of Sciences of the United States of America, 2005, 102(46):16569-16572. 